PRECARIOUS JAPAN 
ANNE ALLISON 


\section{PRECARIOUS JAPAN}


(C) 2013 Duke University Press

All rights reserved

Printed in the United States of America on acid-free paper (a)

Designed by Courtney Leigh Baker. Typeset in Minion Pro by Tseng Information Systems, Inc.

Library of Congress Cataloging-in-Publication Data

Allison, Anne, 1950-

Precarious Japan / Anne Allison.

pages $\mathrm{cm}$

Includes bibliographical references and index.

ISBN 978-0-8223-5548-9 (cloth : alk. paper)

ISBN 978-0-8223-5562-5 (pbk. : alk. paper)

1. Japan-Economic conditions-1989- 2. Japan-Social conditions-1989- I. Title.

HC462.95.A45 2013

$952.05^{\prime} 1-\mathrm{dc} 23 \quad 2013018903$ 